maintaining remission (REM) or low disease activity (LDA) via tight medical control $^{1}$. However, despite remarkable advances in medication, progressive deterioration and deformity of the forefoot sometimes occur if adequate medication is not administered in the early stage. Surgical reconstruction is still required in patients with painful callosity and footwear problems caused by typical forefoot deformity. Recently, patients have expressed a desire to achieve functional REM with a higher quality of life (QOL) and improved mental wellness.

Objectives: The objective of this study was to clarify the systemic effects of forefoot reconstruction on the impaired foot, even in patients who have achieved REM or LDA.

Methods: A prospective cohort study was performed for 63 feet of 50 patients (males: 6, females: 44) with RA who underwent primary elective surgery between October 2012 and September 2014. Both feet underwent surgery on the same day in 13 patients. The average (range) age was $64(42-89)$ years, and the average (range) disease duration was 20 (2-36) years. The procedures performed included shortening oblique osteotomy at the metatarsal neck of the lessor toes in 47 feet, first metatarsophalangeal joint arthroplasty (Swanson) in 44 feet, correction shortening osteotomy (modified Mitchell) at the first metatarsal in 4 feet, and fusion at the first interphalangeal joint in 7 feet, among others. A total of 30 feet in 27 patients (males: 5, females: 22) had a disease activity of REM or LDA just before surgery. The patient-reported outcomes (PROs) were assessed using the Health Assessment Questionnaire-Disability Index (HAQ-DI), EuroQol-5 Dimensions (EQ-5D), Beck Depression Inventory-II (BDI-II), and Patient's General Health using a visual analogue scale of $100 \mathrm{~mm}(\mathrm{Pt}-\mathrm{GH})$. The 28-joint Disease Activity Score using C reactive protein (DAS28-CRP), the Japanese Society of Surgery of the Foot (JSSF) standard rating system (JSSF) for the RA foot and ankle scale ${ }^{2}$, and the Time Up\&Go test (TUG) were also evaluated. All of these items were investigated just before surgery (baseline) and again at 6 and 12 months after surgery.

Results: Overall, the physical function (JSSF, TUG), QOL (EQ-5D), and mental wellness (depression) (BDI-II) were significantly improved at 6 and 12 months after surgery compared to the baseline values $(p<0.05)$. In the REM/LDA group, significant improvement was noted in the physical function (JSSF), QOL (EQ-5D) both at 6 and 12 months after surgery; however, we did not observe any significant changes in the Pt-GH or DAS28-CRP (Table 1).

Table 1: Outcome of surgical inter
patients with rheumatoid arthritis

\begin{tabular}{|c|c|c|c|c|c|c|c|c|}
\hline & & HAQ-DI & EQ-5D & BDI-II & $\begin{array}{l}\text { Pt-GH } \\
(\mathrm{mm})\end{array}$ & $\begin{array}{l}\text { DAS28- } \\
\text { CRP }\end{array}$ & JSSF & $\begin{array}{l}\text { TUG } \\
\text { (sec) }\end{array}$ \\
\hline \multirow{3}{*}{$\begin{array}{l}\text { Total } \\
n=50\end{array}$} & baseline & $\begin{array}{l}0.98 \\
(0.77)\end{array}$ & $\begin{array}{l}0.71 \\
(0.11)\end{array}$ & $\begin{array}{l}11.7 \\
(8.2)\end{array}$ & $\begin{array}{l}30.4 \\
(22.9)\end{array}$ & $\begin{array}{l}2.63 \\
(1.1)\end{array}$ & $\begin{array}{l}61.9 \\
(16.4)\end{array}$ & $\begin{array}{l}10.0 \\
(4.0)\end{array}$ \\
\hline & $\begin{array}{l}\text { PO\# } \\
6 \text { mos. }\end{array}$ & $\begin{array}{l}1.01 \\
(0.8)\end{array}$ & $\begin{array}{l}0.75^{*} \\
(0.13)\end{array}$ & $\begin{array}{l}9.9^{*} \\
(7.0)\end{array}$ & $\begin{array}{l}25 \\
(20.9)\end{array}$ & $\begin{array}{l}2.43 \\
(0.92)\end{array}$ & $\begin{array}{l}78.7^{*} \\
(14.7)\end{array}$ & $\begin{array}{l}9.2^{\circ} \\
(3.0)\end{array}$ \\
\hline & $\begin{array}{l}\text { PO\# } \\
12 \mathrm{mos}\end{array}$ & $\begin{array}{l}1.04 \\
(0.71)\end{array}$ & $\begin{array}{l}0.76^{\circ} \\
(0.15)\end{array}$ & $\begin{array}{l}9.7^{*} \\
(6.9)\end{array}$ & $\begin{array}{l}25.4 \\
(19.7)\end{array}$ & $\begin{array}{l}2.40 \\
(0.89)\end{array}$ & $\begin{array}{l}78.2^{*} \\
(14.3)\end{array}$ & $\begin{array}{l}9.3^{\circ} \\
(3.0)\end{array}$ \\
\hline \multirow{3}{*}{$\begin{array}{l}\text { REM+LDA } \\
n=27\end{array}$} & baseline & $\begin{array}{l}0.78 \\
(0.66)\end{array}$ & $\begin{array}{l}0.73 \\
(0.13)\end{array}$ & $\begin{array}{l}10.3 \\
(7.8)\end{array}$ & $\begin{array}{l}18.9 \\
(18.6)\end{array}$ & $\begin{array}{l}1.85 \\
(0.49)\end{array}$ & $\begin{array}{l}68.0^{\circ .} \\
(15.4)\end{array}$ & $\begin{array}{l}8.6 \\
(2.4)\end{array}$ \\
\hline & $\begin{array}{l}\text { PO\# } \\
6 \text { mos. }\end{array}$ & $\begin{array}{l}0.81 \\
(0.65)\end{array}$ & $\begin{array}{l}0.80^{*} \\
(0.13)\end{array}$ & $\begin{array}{l}8.1^{\circ} \\
(6.3)\end{array}$ & $\begin{array}{l}19.5 \\
(16.7)\end{array}$ & $\begin{array}{l}2.0 \\
(0.60)\end{array}$ & $\begin{array}{l}82.8^{* *} \\
(11.5)\end{array}$ & $\begin{array}{l}8.4^{*} \\
(2.0)\end{array}$ \\
\hline & $\begin{array}{l}\text { PO\# } \\
12 \mathrm{mos}\end{array}$ & $\begin{array}{l}0.89 \\
(0.66)\end{array}$ & $\begin{array}{l}0.80^{*} \\
(0.16)\end{array}$ & $\begin{array}{l}8.7 \\
(7.6)\end{array}$ & $\begin{array}{l}19.4 \\
(16.1)\end{array}$ & $\begin{array}{l}2.0 \\
(0.57)\end{array}$ & $\begin{array}{l}81.4^{* *} \\
(11.8)\end{array}$ & $\begin{array}{l}8.4 \\
(2.5)\end{array}$ \\
\hline
\end{tabular}

Mean(SD) $: D<0.05$ compared to baseline. $*: p<0.01$ compared to baseline

Conclusions: Achieving REM or LDA is not the ultimate goal of treatment for patients with painful callosity and footwear problem functional loss. A higher QOL and improved function can be achieved by surgical intervention in the deformed forefoot.

References:

[1] Smolen JS, Breedveld FC, Burmester GR, et al. Treating rheumatoid arthritis to target: 2014 update of the recommendations of an international task force. Ann Rheum Dis. 2016;75(1):3-15.

[2] Niki H, Aoki H, Inokuchi S, et al. Development and reliability of a standard rating system for outcome measurement of foot and ankle disorders I: development of standard rating system. J Orthop Sci. 2005:10:457-465.

Disclosure of Interest: None declared

DOI: 10.1136/annrheumdis-2017-eular.3393

\section{AB0372 ASSOCIATED FACTORS OF CERVICAL AND LUMBAR SPINAL INSTABILITY IN PATIENTS WITH RHEUMATOID ARTHRITIS}

Y. Sugimura ${ }^{1}$, N. Miyakoshi ${ }^{2}$, T. Kashiwagura ${ }^{3}$, M. Kobayashi ${ }^{4}$, T. Aizawa ${ }^{5}$, H. Aonuma ${ }^{6}$, Y. Shimada ${ }^{2}{ }^{1}$ Orthopedic Surgery, Nakadori General Hospital; ${ }^{2}$ Orthopedic Surgery, Akita University Graduate School of Medicine; ${ }^{3}$ Orthopedic Surgery, Akita City Hospital, Akita; ${ }^{4}$ Orthopedic Surgery, Hiraka General Hospital, Yokote; ${ }^{5}$ Orthopedic Surgery, Kita Akita Municipal Hospital, Kitaakita; ${ }^{6}$ Orthopedic Surgery, Kakunodate Municipal Hospital, Senboku, Japan

Background: Few studies have compared rheumatoid arthritis (RA)-related disorders of the cervical and lumbar spine.
Objectives: The objectives of this study were to examine the prevalence of and risk factors for cervical and lumbar spinal instability in patients with RA.

Methods: From a total of 1,843 patients registered in the Akita Orthopedic Group on Rheumatoid Arthritis (AORA), 135 patients [118 women, 17 men; mean age, $66(41-84)$ years; mean disease duration, 14 (1-63) years] who underwent a radiographic examination were enrolled in this study. In the cervical spine, we defined instability as one of the following characteristics: (1) atlantodental interval (ADI) $>3 \mathrm{~mm}$, (2) Ranawat value $<13 \mathrm{~mm}$ on a neutral plain radiograph, or (3) anteroposterior translation $>3 \mathrm{~mm}$ at the subaxial cervical spine on an anteroposterior bending plain radiograph. In the lumbar spine, instability was defined as anteroposterior translation $>3 \mathrm{~mm}$ on a neutral plain radiograph.

At the time of radiographs evaluation, demographic characteristics, clinical variables, medical history and current medications were investigated.

The patients were classified into two groups: with both cervical and lumbar spinal instabilities and without. The independent risk factors for both cervical and lumbar spinal instabilities were then determined using multivariate logistic regression analysis.

Results: Forty-six (34.1\%) patients exhibited cervical spinal instability, and 50 (37.0\%) patients exhibited lumbar spinal instability. Twenty-four patients (17.8\%) exhibited both cervical and lumbar spinal instability. The presence of both cervical and lumbar spinal instability was significantly and independently associated with disease duration (OR: 1.06; 95\% Cl: 1.01-1.12).

Conclusions: The prevalence of both cervical and lumbar spinal instability in patients with RA was $17.8 \%$. Disease duration was independent risk factor for presence of both cervical and lumbar spinal instability in this study.

Disclosure of Interest: None declared

DOI: 10.1136/annrheumdis-2017-eular.6649

\section{AB0373 ANALYSIS OF RISK FACTOR FOR LOCOMOTIVE SYNDROME IN PATIENTS WITH RHEUMATOID ARTHRITIS: DATA FROM CHIKARA STUDY}

Y. Yamada, M. Tada, K. Mandai, N. Hidaka. Department of orthopedics surgery, Osaka City General Hospital, Osaka City, Japan

Background: Patients with rheumatoid arthritis (RA) are at a higher risk for sarcopenia due to joint destruction and chronic inflammation ${ }^{*} 1$, which can lead to locomotive syndrome (LS), i.e., being restricted in the ability to walk or lead a normal life owing to a dysfunction in one or more of the parts of the musculoskeletal system ${ }^{*}$. The prospective observational CHIKARA study (Correlation research of sarcopenia, skeletal muscle and disease activity in rheumatoid arthritis; registration number UMIN000023744) was begun in 2016 to investigate the correlation between RA disease activity and sarcopenia and LS.

Objectives: We investigated the relationship between LS and disease activity at baseline in patients with RA.

Methods: One hundred patients (78\% women; average age, $66 \mathrm{y})$ enrolled in the CHIKARA study were examined for body weight, muscle mass, fat mass, predicted bone mass, basal metabolic rate (BMR), leg muscle score, etc., using a body composition analyzer. Laboratory data, disease activity, Health Assessment Questionnaire (HAQ) and treatment were also investigated. LS was diagnosed using a questionnaire called Locomo- 5 . We investigated the correlation between LS and each status using univariate and multivariate analyses.

Results: Fifty-two percent of the patients with RA that we examined had LS. Mean disease duration was 5.5 years and mean DAS28-ESR was 3.55. Table 1 shows the risk factors for LS. Univariate analysis showed that age, percent body fat, body weight, visceral fat rating, leg muscles score, rheumatoid factor status and $\mathrm{HAQ}$ had significant associations to LS. Leg muscle score and HAQ were detected as significant factors by multivariate analysis. Patients whose leg muscle score was less than 90 had a significantly higher prevalence of LS by ROC curve analysis (Odds ratio 3.77, $p=0.001$ ). Disease activity and use of glucocorticoids or biological agents showed no significant relationship.

Table 1. Risk factors for locomotive syndrome in patients with rheumatoid arthritis

\begin{tabular}{|c|c|c|c|c|c|}
\hline & \multicolumn{2}{|c|}{ Univariate } & \multicolumn{3}{|c|}{ Multivariate } \\
\hline & $\mathrm{R}$ & $p$ value & Odds ratio & 95\% Confidence Interval & $P$ value \\
\hline Age, y & 0.255 & 0.01 & - & - & - \\
\hline$\%$ body fat & 0.244 & 0.014 & - & - & - \\
\hline$\%$ body water & -0.215 & 0.032 & - & - & - \\
\hline Visceral fat rating & 0.205 & 0.041 & - & - & - \\
\hline Leg muscle score & -0.359 & $<0.001$ & 0.91 & $0.84-0.97$ & 0.005 \\
\hline Rheumatoid factor & 0.221 & 0.027 & - & - & - \\
\hline \multicolumn{6}{|l|}{ Health Assessment } \\
\hline Questionnaire & 0.460 & $<0.001$ & 8.78 & $2.66-29.0$ & 0.001 \\
\hline
\end{tabular}

Conclusions: Lower leg muscle score and higher HAQ score are independent risk factors for LS among patients with RA.

References:

[1] Inui K., Koike T., Tada M., et al. Sarcopenia is apparent in patients with rheumatoid arthritis, especially those with biologics -TOMORROW study-. EULAR 2015 abstract (AB0359).

[2] Nakamura K., Ogata T. Locomotive Syndrome: Definition and Management. Clin Rev Bone Miner Metab. 2016; 14(2): 56-67.

Disclosure of Interest: None declared 
DOI: 10.1136/annrheumdis-2017-eular.3637

\section{Rheumatoid arthritis - anti-TNF therapy}

\section{AB0374 FLARE INCIDENCE AND PREDICTIVE FACTORS IN A POPULATION OF PATIENTS WITH RHEUMATOID ARTHRITIS UNDER OPTIMISED TREATMENT WITH ADALIMUMAB AND INFLIXIMAB}

A. Pieren ${ }^{1}$, C. Plasencia ${ }^{1}$, D. Pascual-Salcedo ${ }^{2}$, M.B. Paredes ${ }^{1}$, A. Balsa ${ }^{1}$.

${ }^{1}$ Rheumatology; ${ }^{2}$ Immunology, Hospital la Paz, Madrid, Spain

Background: Anti-TNF are nowadays widely used for the treatment of Rheumatoid Arthritis (RA), which has drastically changed the prognostic of the disease,carrying an important healthcare expense.This is why,optimisation seems a successful strategy that should not be linked to a worse become of our patients' clinical evolution.

Objectives: Describe a population of patients with RA under optimised treatment with Adalimumab (Ada) and Infliximab (Ifx).Study the incidence of flares and establish predictive factors of flares at baseline and pre-optimization.

Methods: Observational study of the prospective cohort RA-Paz. All the patients diagnosed of RA under treatment with Ifx and Ada between Jan.2000 and Dec.2016 of the day-care unit of La Paz Hospital,were included.Demographic data,clinical activity and blood sample results were collected at baseline, preoptimization (pre-op)and at 3,6,9,12,18 and 24 months.Drug serum trough levels were measured under ELISA in each visit.Optimal range for Ifx was described as drug concentration between $1000-4000 \mathrm{ng} / \mathrm{ml}$ and $1500-5000 \mathrm{ng} / \mathrm{ml}$ for Ada.Optimisation was defined as drug use below standard dose.Flares were collected from the pre-op visit.Flare was described as clinical worsening which led to a therapeutic change or a DAS28 $>3.2$ and DeltaDAS28 $>0$,6. Predictive factors of flare at baseline and pre-op were evaluated with a uni and multivariate analysis. Statistical study was performed with the statistical program SPSS.

Results: Of the 271 patients diagnosed of RA, 74 patients were optimised (44 under Ada and 30 under Ifx). Baseline demographic caracteristics are shown in the table below.During the 24 months after the pre-op visit, 55,4\% (41)of the patients presented at least one flare, with an average of 1,38 flares [1-5]. Most of the patients $(53.7 \%, 22 / 41)$,were controlled with the adjustment of non biological treatment.Only $39,0 \%(16)$ of the patients, had to go back to the previous optimised dose and $7,3 \%$ (3)to the standard dose.88\% (39/41)were controlled after the dose modification.104 flares were collected, $33 \%$ (34) happened at the 3rd month and $20 \%(21)$ at 24th. In the population who presented flares, we observed a persistent higher DAS Vs the patients who never presented flares (DAS pre-op $3,20 \pm 1,16$ Vs $2,26 \pm 0,59$; DAS 24month $3,61 \pm 1,13 \mathrm{Vs} 2,10 \pm 0,65 ; \mathrm{p}=0,007)$. A least proportion of patients with flares were in supra-optimal range $(13,3 \%$ with flares vs $26 \%$ without, $p=0,007)$. At baseline, no clinical factors were predictive of flare. Nor were blood sample results. In contrast, a higher disease activity, measured by DAS pre-op $(p=0,004)$, a worst EULAR answer $(p=0,027)$ and not being in supra-optimal range $(p=0,032)$, were statistically correlated with flares development at the univariate analysis. Time to the optimisation tended to the significance $(\mathrm{OR}=1,152 ; \mathrm{p}=0.08)$. In the multivariate analysis, only a higher DAS pre-op (OR:2,00,[1,08-3,73])and being in optimal (OR:5,90, [1,38-25,2])and sub-optimal range $(\mathrm{OR}=6,05[1,28-28,7])$, were independently correlated.

\begin{tabular}{|c|c|}
\hline & $\mathrm{N}$ Total $=74$ \\
\hline Sex & $\begin{array}{l}\text { Women } 83,8 \%(62) \\
\text { Men } 16,2 \%(12)\end{array}$ \\
\hline Age & $64,1(+/-12,6)$ \\
\hline Age at diagnosis & $41,6(+/-14,0)$ \\
\hline bDMARD & $\begin{array}{l}\text { Ada } 59,5 \%(44) \\
\text { IFX } 40,5 \%(30)\end{array}$ \\
\hline $\begin{array}{l}\text { Time to the beginning of } \\
\text { bDMARD (years) }\end{array}$ & $10,7(+/ \cdot 7,50)$ \\
\hline $\begin{array}{l}\text { Time to optimisation } \\
\text { (years) }\end{array}$ & $4,70(+/-3,12)$ \\
\hline Treatment duration (years) & $8,80(+/-4,00)$ \\
\hline $\mathrm{RF}+$ & $75,7 \%(56)$ \\
\hline $\mathrm{ACPA}+$ & $73,0 \%(54)$ \\
\hline Smoking & $\begin{array}{l}\text { No smokers } 68.9 \%(51) \\
\text { Smokers } 17,6 \%(13) \\
\text { Ex smokers } 12,2 \%(9)\end{array}$ \\
\hline BMI & $25,6(+/-4,61)$ \\
\hline Methotrexate (MTX) & $74,3 \%(55)$ \\
\hline Average dose MTX $(\mathrm{mg} / \mathrm{sem})$ & $12,3(+/-8,60)$ \\
\hline Other sDMABD & $54,1 \%(40)$ \\
\hline SDMARD & $\begin{array}{l}\text { Leflunemide } 62,5 \% \text { (25) } \\
\text { Salazopyxine } 15 \% \text { (6) } \\
\text { Hxdroxychloquine 10\% (4) } \\
\text { Leflunemide+SZP 5\% (2) } \\
\text { Leflunemida+HCQ 5\% (2) } \\
\text { SZP+HCQ 2,5\% (1) }\end{array}$ \\
\hline Prednisone & $37,8 \%(28)$ \\
\hline Prednisone dose (mg/dia) & $1,89(+/ \cdot 2,62)$ \\
\hline DAS baseline & $5,03(+/-1,35)$ \\
\hline VSG baseline & $34,7(+/-18,9)$ \\
\hline PCR baseline & $10,2(+/-12,5)$ \\
\hline
\end{tabular}

Conclusions: In our cohort of optimised patients, we noted a high proportion of flares. However, flares were controlled with dosage readjustment without needing a treatment change. Independently correlated predictive factors for flares were a higher disease activity measured by DAS and not being in therapeutic range in the pre-optimisation visit.

Disclosure of Interest: None declared

DOI: 10.1136/annrheumdis-2017-eular.6859

\section{AB0375 THE EFFECT OF CONCOMITANT USE OF METHOTREXATE ON THE CLINICAL ACTIVITY IN PATIENTS WITH RHEUMATOID ARTHRITIS UNDER ANTI-TNFTHERAPY}

A. Martinez-Feito ${ }^{1}$, C. Plasencia ${ }^{2}$, B. Hernandez-Breijo ${ }^{1}$, A. Jochems ${ }^{1}$, C. Diego ${ }^{3}$, A. Villalba ${ }^{2}$, D. Peiteado ${ }^{2}$, L. Nuño ${ }^{2}$, P. Nozal ${ }^{3}$, A. Balsa $^{2}$, D. Pascual-Salcedo ${ }^{1} .{ }^{1}$ Immuno-Rheumatology research group; ${ }^{2}$ Rheumatology; ${ }^{3}$ Immunology, University Hospital la Paz, madrid, Spain

Background: Several publications in rheumatoid arthritis (RA) have demonstrated a beneficial effect of concomitant methotrexate (MTX) use with TNF inhibitors (TNFi), mainly because of the MTX effect in reducing immunogenicity. In a previous work in the RA-La Paz cohort, we found that the concomitant use of MTX had a positive effect on the pharmacokinetics of serum TNFi levels, decreasing the immunogenicity of these drugs. Furthermore, the MTX effect was dose-dependent, being greater at high MTX dose. Currently, we investigate the effect of concomitant MTX use on the clinical response.

Objectives: To investigate the MTX influence on the clinical response in the RA-La Paz cohort treated with Infliximab (Ifx), Adalimumab (Ada) or Etanercept (Etn) at one year of treatment.

Methods: This is an observational study from a prospective cohort from the Biological Unit of the University Hospital La Paz, Madrid, Spain that analysed a total of 293 RA patients treated with Ifx (112 patients), Ada (71 patients) and Etn (110 patients). Patients were grouped according to the MTX dose: no MTX, low dose (LD: $\leq 12.5 \mathrm{mg} /$ week), intermediate dose (ID: 15-17.5 mg/week) and high dose (HD: $\geq 20 \mathrm{mg} /$ week). For this study, the clinical response was evaluated by DAS28-ESR and the clinical improvement by $\triangle \mathrm{DAS} 28$. Data were collected at baseline, 0.5 and 1 year of TNFi treatment. Statistical analysis was performed using GraphPad Prism 6.0 software.

Results: Out of 293 RA patients (pts) under TNFi treatment, 184 (71 with Ifx, 40 with Ada and 73 with Etn) were included. In this cohort, $128(70 \%)$ pts used concomitantly MTX (91\% oral administration) and $56(30 \%)$ pts were in monotherapy. No differences in DAS28 were found at baseline between patients with or without MTX $(p=0.8)$.

After one year of treatment, pts with TNFi $+\mathrm{MTX}$ have a significantly lower DAS28 than patients without MTX ( $3.3 \pm 1.3$ vs $3.9 \pm 1.1 ; p=0.004)$. When analyzing the DAS28 values in relationship to the MTX dose, statistical differences are observed with use of $\mathrm{HD}$ ( $>20 \mathrm{mg} / \mathrm{week})(3.1 \pm 1.3$ with $\mathrm{HD}$ vs $3.9 \pm 1.1$ without MTX; $p=0.001)$ but not with intermediate $(3.4 \pm 1.2$ with ID vs $3.9 \pm 1.1$ without MTX; $p=0.06)$ or low MTX dose $(3.8 \pm 1.6$ with LD vs $3.9 \pm 1.1$ without MTX; $p=0.4)$ at 1 year of therapy.

Clinical improvement by $\triangle \mathrm{DAS} 28$ was higher in patients with TNFi +MTX than in patients without MTX $(1.7 \pm 1.4$ vs $1 \pm 1.3 p=0.007)$. This effect was observed with all MTX doses $(1.7 \pm 1.5$ with HD vs $1 \pm 1.3$ without MTX, $\mathrm{p}=0.01 ; 1.6 \pm 1.3$ vs with ID $1 \pm 1$.3without MTX, $p=0.03 ; 1.8 \pm 1.3$ with LD vs $1 \pm 1.3$ without $M T X, p=0.01$ ). Conclusions: In the RA-La Paz cohort under TNFi treatment, the concomitant use of MTX has a positive effect on the clinical activity, mainly when high dose of MTX is used. Moreover, we demonstrate a positive effect of any MTX dose on the clinical improvement at one year of treatment.

Disclosure of Interest: None declared

DOI: 10.1136/annrheumdis-2017-eular.2884

\section{AB0376 CARTILAGE OLIGOMERIC MATRIX PROTEIN, A BIOMARKER OF ARTHRITIS, COULD BE USEFUL FOR PREDICTING THE RESPONSE TO BIOLOGIC THERAPY IN RHEUMATOID ARTHRITIS?}

B.I. Gavrila ${ }^{1}$, C. Ciofu ${ }^{1}$, C. Mihai ${ }^{1}$, G. Udrea ${ }^{1}$, M. Bojinca ${ }^{1}$, V. Stoica ${ }^{1}$, E. Panaitescu ${ }^{2}{ }^{1}$ Department of Internal Medicine and Rheumatology Cantacuzino Hospital; ${ }^{2}$ Medical Informatics and Biostatistics, Carol Davila University of Medicine and Pharmacy, Bucharest, Romania

Background: introduction of biologic therapy has revolutionized the treatment of Rheumatoid Arthritis (RA). Despite these advances, $20-40 \%$ of the patients are declared nonresponders to at least one of the therapies (1).High costs and patient exposure to severe adverse reactions (ex. infections) determined the need to identify biomarkers that can distinguish pretreatment responders versus nonresponder patients.

Objectives: evaluating the predictive role for the response to anti tumor necrosis factor therapy (anti-TNF) of cartilage oligomeric matrix protein (COMP), a specific serological marker, which evaluates the articular cartilage degradation and its turnover.(2)

Methods: prospective and observational study including 64 patients followed 12 months with active RA, uncontrolled by conventional synthetic DMARDs.Clinical assessment was performed at 0,6 and 12 months according to ACR criteria approved by OMERACT and evaluation of treatment response according to EULAR criteria (good/moderate /nonresponder). 